significantly reduced by pseudopregnancy this therapy is valuable as a holding measure, preserving fertility for at least a few years. Pseudopregnancy is also valuable in cases with lesions inaccessible to surgery when castration might be the only alternative treatment. Even if relief is only temporary, hormonal treatment may enable surgical menopause to be postponed to an age when it is likely to be better tolerated. Precise diagnosis before treatment can be made without laparotomy. Formerly we used culdoscopy for this purpose, but often unsuccessfully because of adhesions in the pouch of Douglas. With the more versatile laparoscope this difficulty can almost always be overcome. Nausea and weight gain occurred in $25-30 \%$ of our cases, but the former usually ceased after about two months and normal weight was reestablished a few weeks after the completion of treatment. Thromboembolic disease was not a problem.

In view of the foregoing I would urge gynaecologists not to discand the weapon of pseudopregnancy. It is often curative and even when further treatment, either hormonal or surgical, is required its contribution to the solution of what Andrews and Larsen call "a vexing clinical problem" is too valuable to be ignored.-I am, etc.,

\section{J. A. Chalmers}

Worcester Royal Infirmary

1 Andrews, W. C., and Larsen, C. D., American Yournal of
118, 643 .

Chalmers, J. A., in Proceedings of Second European Congress on Sterility, Dubrovnik, 1969, p. 19. American fournal of Obstetrics and Gynecology, 1974, 118, 650 .

\section{Pitocin Buccal in Late Pregnancy}

SIR,-In recent years we have pursued the policy, in certain cases, of prescribing Pitocin Buccal (oxytocin) tablets (ParkeDavis) in late pregnancy to "ripen" the cervix prior to inducing labour. Furthermore, from talking to colleagues, we believe we are not alone in advocating this practice. We have nevertheless been doubtful as to the efficacy of such therapy, though at first glance the concept of "priming the uterus" with repeated small doses of oxytocin would seem an attractive one.

We therefore undertook a small pilot study, conducted as a double-blind trial and in conjunction with Dr. David Evans of ParkeDavis. In this trial one Pitocin Buccal tablet (200 units oxytocin) or a placebo, was given three times a day to 44 primigravidae from 38 weeks onwards until delivery. Patients were fully informed and only those who were both certain of their dates and had had uncomplicated pregnancies were selected. All patients took a minimum of 21 tablets (seven days), the mean number being 57 for the 22 who took the active preparation and 42 for the 22 who took the placebo.

Cervical effacement (as judged by a cervix of more than $2 \mathrm{~cm}$ length at the beginning of therapy diminishing to less than $1 \mathrm{~cm}$ length at the onset of labour or induction) occurred in only $61 \%$ of those patients taking the active preparation, and when this figure is compared with $50 \%$ effacement in those taking placebo the difference is not significant. When we looked at the duration of the first stage of labour the results were likewise not significantly different in the two groups, though a mean of 7.6 hours for the Pitocin Buccal patients undoubtedly compared favourably with $10 \cdot 2$ hours for those taking placebo.

Our results lead us to conclude, therefore, that oxytocin as used in the form described here has no clinically detectable effect on uterine activity either in late pregnancy or labour. However, when one takes into account that as little as five years ago the mean duration of the first stage of labour at Guy's was 13.35 hours it is possible that any effect the oxytocin may be having in this respect is masked by the active approach to management of labour.-We are, etc.,

\section{T. H. COLTART} T. G. NASH

\section{Department of Obstetrics,}

Guy's Hospital Medical School,
London S.E.1

\section{Eugynon 30 and Dermatitis}

SIR,-Dr. S. J. Jachuck and Dr. H. L. Franks (3 August, p. 347) may be interested to hear of a woman who developed urticaria each time she took an oral contraceptive pill. In 1967, 1972, and 1974 she was prescribed Lyndiol-2.5, Norinyl-1, and Microgynon 30 respectively. On each occasion, after only a few tablets, she developed a mild diffuse urticarial rash, mainly on the limbs and chest. She continued with the first two drugs for only two weeks but was persuaded to complete the course of Microgynon 30. The rash faded during the pillfree week. Piriton $4 \mathrm{mg}$ was given with the second course of pills to see if it would modify the reaction. It had no effect and the woman stopped the pill of her own accord on the fifth day. During her first pregnancy, in 1957, she was found to be allergic to nickel but her subsequent pregnancies in 1961 and 1967 were uneventful. There is neither hormone, dye, nor manufacturer common to these oral contraceptives, and no light has been shed on the problem so far.-I am, etc.,

Family Planning Association,

DELIA F. MORRIS

Wellingtanning

\section{Tetracycline-resistant Group A Streptococci}

SIR,-Dr. R. J. Fallon (22 June, p. 663) expressed interest in the prevalence of tetracycline resistance among streptococci in different areas of Britain. Though Ayrshire has both social and commercial links with Glasgow the incidence of tetracyclineresistant Lancefield group A streptococci (Str. pyogenes) observed here since 1970 differs markedly from that reported by Dr. Fallon for the Glasgow (north) area only some 30 miles $\left(48 \mathrm{~km}\right.$ ) away. ${ }^{1}$ In $19703.5 \%$ of strains isolated from hospitals and general practice in Ayrshire were resistant, in 1971 $14.2 \%$, in $197236.8 \%$, and in $197333.3 \%$. Currently (the first half-year of 1974) the incidence is $19.4 \%$. Quarterly figures reveal a much wider range of incidence, however, from $1.1 \%$ in the second quarter of 1970 to $53.7 \%$ in the same quarter of 1973.

Invariably during this time respiratory tract isolates overall have exceeded numerically those of non-respiratory origin, with a fairly even distribution not only year by year but also between hospitals and general practice. Interestingly, the twin peakincidences of tetracycline-resistance of $51.5 \%$ (fourth quarter of 1972) and $53.7 \%$ both coincided with unusually high but non-epidemic incidences of non-respiratory isolates, though not of Str. pyogenes generally. Between these two quarter-years was one with an observed incidence of $26.8 \%$ for tetracycline-resistant Str. pyogenes, and for that reason as much as any other I hesistate to predict what trend our last quarter's incidence of $22.2 \%$ is supposed to show. As reiterated in your leading article on tetracyclines (25 May, p. 400), resistance is now common enough to make that group of antibiotics unsuitable as a first choice for infections caused by Str. pyogenes. - I am, etc., JOHN A. N. EMSLIE

Microbiology Department

Irvine, Ayrshire

Fallon, R. J., British Medical fournal, 1973, 4,

\section{Antiemetics, Prolactin, and Breast Cancer}

SIR,-We agree with Dr. H. W. C. Ward (20 July, p. 169) that drugs which raise circulating prolactin levels should not be given to patients with breast cancer. Following our report on metoclopramide's potent prolactin-releasing properties (29 June, p. 729) we support his suggestion that it is best avoided in such patients.

It is well established that the phenothiazines raise circulating prolactin levels. ${ }^{1}$ We have shown that proohlorperazine, a phenothiazine, which Dr. Ward suggested as an alternative to metoclopramide, also raises prolactin in man, thus making it, too, unsuitable. To find a suitable antiemetic which was without effect on prolactin levels we have screened a number of compounds. Of these cyclizine $50 \mathrm{mg}$ intramuscularly did not alter circulating prolactin levels. We therefore recommend that cyclizine rather than prochlorperazine should be the antiemetic of choice for patients with breast cancer undergoing radiotherapy.-We are, etc.,

M. O. THORNER G. VoLANS G. M. BESSER

St. Bartholomew's Hospital, A. S. MCNEILLY

London E.C.1

1 Turkington, $\mathbf{R}$. W., American fournal of Medi-

Blood Donors and the Transfusion Service

SIR,-While agreeing with much of your provocative leading article (27 July, p. 212) I must protest at your statement that the British blood transfusion service is clearly a lame duck. Foreigners reading your journal -and many do-might be forgiven for believing that our blood transfusion service, 
once acknowledged throughout the world as firct class, is now moribund. Voluntary donors, whose altruism you rightly praise, might well feel that their efforts and generosity are being squandered. I agree that our blood transfusion service requires an injection of capital and forward planning on a national basis, but I disagree that there has been a steady decline in it since the late 1950s.

I have worked in various sections of our blood transfusion service since 1940 and I think that the period of greatest progress has been the past seven years. Firstly, there has been the change from glass bottles to plastic packs which has facilitated the production of various blood components and plasma fractions. I have witnessed the preparation of large quantities of cryoglobulin precipitate to meet the demands of our regional haemophilia centre, and of adequate amounts of anti-D immunoglobulin for the prevention of $\mathrm{Rh}$ haemolytic disease. Banks of frozen red cells have been established, total screening of donations for the hepatitis B antigen has been introduced, tissue typing has been developed, and platelet concentrates, some coagulation fractions, specific immunoglobulins, and albuminoid preparations may have been provided. All these developments have required planning and money. More financial help is now required to continue this progress.

There are two important practical issues you do not mention. One concerns management, the other the clinician. Many of the processes in modern transfusion practice involve freshly donated blood and continue during the evening and throughout the night. Management is unwilling to recognize that these processes require skilled staff working unsocial hours. The financial reward for this type of work in the N.H.S. compares most unfavourably with industrial processing. The clinical issue is the need to use red cells rather than whole blood. You refer to progress in America, where it has been found that the provision of enough blood components depends on the willingness of clinicians to use red cells in many clinical situations in which they formerly used whole blood. I have found that most of my clinical colleagues are willing to do this in expectation of receiving more blood components. Already $40 \%$ of our intake of blood is being accepted by hospitals in the form of red cells. Rightly, however, clinicians expect to receive in return for this co-operation large quantities of a variety of components. We are making good use of that valuable commodity, donor blood. Now we require to make the optimal use, and this can be achieved only by effective national planning and by a large volume financial transfusion. -I am, etc.

Glasgow and West of Scotland Blood Transfusion Service, Carluke, Lanarkshire

SIR,-The views and statements attributed to my coauthor, A. J. Culyer, and me in your leading article (27 July, p. 212) are, to say the least, serious distortions of our actual position. Our monograph ${ }^{1}$ sought to show that, contrary to the opinion of the late R. M. Titmuss, blood was in fact an economic good and therefore fully amenable to normal economic analysis. In the course of our monograph we pointed out that on the bacis of no evidence whatsoever Professor Titmuss had asserted that "in the U.K. there was no shortage of blood." In order to test medical opinion on this point we conducted the postal survey which you choose to describe as "extraordinary." We, however, made no claims of scientific rigour for this exercise but rather pointed out that it offered "no more than a subjective and impressionistic indication of adequacy" demonstrating "the need for more detailed investigations than we have been able to undertake to date."

Since we wrote in 1968 there has been, to my knowledge, no further survey (extraordinary or otherwise), and so I should be most interested to learn of the source of your statement that "there is no shortage of voluntary donors in Britain." You may well be right. I, however, simply admit to not knowing. It is not in any case true that our conflict with Professor Titmuss "rests on the assumption ... that there is a genuine national shortage of blood." Rather it rests on the nature of giving as against selling and on the whole role of economic analysis within the social context.

In 1968 we claimed that if our monograph "has done nothing else it has demonstrated that prediction is difficult and planning is impossible without more information than anyone until recently appears to have considered worth collecting, let alone publicizing." This observation at least appears to have your support.-I am, etc.,

Department of Economics

Michael H. COOPER

Cooper, M. H., and Culyer, A. J., The Price of 1968.

Titmuss, R. M., Choice of the Welfare State, p
15. London, Fabian Society, 1967 .

\section{Hypothermia, Thrombosis, and Acute Pancreatitis}

SIR,-In reply to Dr. D. MacLean's letter (25 May, p. 446) there are a few points to be clarified.

Firstly, it is agreed that ischaemia even without thrombosis could conceivably produce pancreatitis in accidental hypothermia Nevertheless, in the case which Dr. Hoffbrand and I reported (30 March, p. 614) pancreatic venous thrombosis was present.

Secondly, Dr. MacLean states that in his experience patients with accidental hypothermia have signs of an acute abdomen only in the presence of associated perforated gastric or duodenal ulcers with peritonitis or mesenteric vascular occlusion with smallbowel gangrene. Our patient had neither of these conditions, yet signs of an acute abdomen were present. Dr. MacLean's failure to elicit signs of an acute abdomen in his patients could possibly have been due to insensitivity of the patient related to the severity of the hypothermia and the level of consciousness-or to the absence of thrombosis.

Thirdly, necropsy in our case showed an extremely florid and extensive acute haemorrhagic pancreatitis with lipophages seen histologically as far away as in the paraoesophageal lymph node, and it is doubtful whether the patient would have survived long enough to develop secondary hypo- thermia as Dr. MacLean suggests, though it is agreed that secondary hypothermia can occur from a primary serious underlying illness, with venous thrombosis as an piphencmenon, if time permits.

Finally, Dr. MacLean is referred to the letter from Dr. Hoare and his colleagues immediately following his own.-I am, etc.,

\section{E. SAVIDES}

Area Department of Pathology Royal Devon and Exeter Hospital (Wonford),
Exeter

\section{Swimmers' Ears}

SIR,-Your leading article (27 July, p. 213) tends to give an untrue picture of ear problems in Scuba diving, or at least so far as the British Sub-aqua Club is concerned.

The medical standard required of divers is high and examination includes a careful study of the ears. Any prospective diver with chronic otitis externa would be dissuaded from diving and those with collections of cerumen would be advised to have them removed. In the event, normal Scuba diving does not seem to produce undue otitis externa, possibly because the exposure rarely lasts longer than about three-quarters of an hour at a time. Furthermore, it is doubtful whether the ear becomes full of water on deep diving as the compression of the wet suit over the ear may be responsible for keeping much of the water out.

Your advice that "Vaseline-coated ear plugs might help" goes against all present teaching for underwater activities. The presence of a plug in the external auditory canal will, at depth, lead to a condition known as reversed ear, in which haemorrhagic blisters may form between the plug and the eardrum. This in itself is likely to cause a considerable otitis externa.-I am, etc.,

Southampton

A. M. BIRT

** Certainly ear plugs could be dangerous for divers, and this recommendation in our leading article was a mistake. However, they can be of value for swimmers troubled by otitis externa.-ED., B.M.f.

SIR,-I was interested to read your suggestion (27 July, p. 213) that divers with otitis externa might be helped by using Vaselinecoated ear plugs, for I have always understood that such appliances are considered to be hazardous. The comparatively small head of water encountered by a diver, even while plunging from the side of a pool, could drive the plug deeply into the meatus with consequent barotrauma to the drums. If he were fortunate not to experience this painful occurrence while actually diving the chance of barotrauma from the suction on removing such well-greased plugs from the external canal may not only be painful but could lead to drum rupture.

Those who are accustomed to skin-diving or aqualunging will know the importance not only of a clear eustachian tube but also of a clear external auditory meatus in order that adequate pressure equalization manoeuvres may be carried out. The insertion of plugs would prevent this. May I suggest that there is no place for Vaseline-coated ear 